\title{
Evaluation of pre-chemotherapy antiemetic prescriptions in a hospital unit
}

\begin{abstract}
Introduction: Antineoplastic drugs, due to their high toxicity, can lead to adverse reactions to drugs, such as emesis, which causes discomfort to the patient. These drugs can be classified according to emetogenic potential and have appropriate treatment protocols. Objectives: The aim of this study is to evaluate whether there is compliance between antiemetic prescription in patients receiving antineoplastic treatment in a hospital unit, according to preestablished emesis prevention protocols. Methods: This is a cross-sectional retrospective study of chemotherapy prescriptions analysis from January to April 2017. Data were analyzed according to the National Comprehensive Cancer Network 2017 Acute Emesis Prevention Protocol. Nonconformities were classified. in: wrong medicine; wrong dose; wrong administration frequency and wrong administration route. Results: Of the 919 prescriptions analyzed, $83 \%$ did not comply with the protocol. The most common nonconformity found in the study was the wrong dose with the most prevalent scenario being the dexamethasone dose above the required dose. Conclusion: Most of the prescriptions analyzed did not comply with the pre-established protocol. This increases the likelihood of adverse drug reactions, does not effectively prevent emesis, thereby increasing patient weakness, decreasing quality of life, and wasting resources.
\end{abstract}

Keywords : oncology, antineoplastic agents, antiemetics.

\section{Avaliação das prescrições de antieméticos na pré-quimioterapia em uma unidade hospitalar}

\section{Resumo}

Introdução: Os medicamentos antineoplásicos, devido a sua alta toxicidade, podem acarretar em reações adversas a medicamentos, como a êmese, que gera desconforto ao paciente. Esses medicamentos podem ser classificados de acordo com o potencial emetogênico e possuem protocolos adequados de tratamento. Objetivos: O objetivo desse trabalho é avaliar se há conformidade entre a prescrição dos antieméticos de pacientes em tratamento com antineoplásicos em uma unidade hospitalar, de acordo com protocolos de prevenção da êmese preestabelecidos. Métodos: Trata-se de um estudo retrospectivo transversal da análise de prescrições de quimioterapia, no período de janeiro a abril de 2017. Os dados foram analisados de acordo com o protocolo de prevenção da êmese aguda da National Comprehensive Cancer Network 2017. As não conformidades foram classificadas em: medicamento errado; dose errada; frequência de administração errada e via de administração errada. Resultados: Das 919 prescrições analisadas, $83 \%$ não estavam em conformidade com o protocolo. A não conformidade mais encontrada no estudo foi a dose errada tendo como cenário mais prevalente a dose da dexametasona acima da necessária. Conclusão: A maior parte das prescrições analisadas não se encontrava em conformidade como protocolo preestabelecido. Este fato aumenta a probabilidade de ocorrer reaçãoadversa a medicamento, não previne de forma eficaz a êmese aumentando assim adebilidade do paciente, diminui a qualidade de vida, além do desperdício de recursos.

Palavras-chaves: oncologia, antineoplásico, antieméticos.

\section{Universidade Federal Fluminense}

Submitted: $13 / 09 / 18$

Resubmitted: 21/11/19

Accepted: 28/12/19

Blind Reviewers

DOI: $10.30968 /$ rbfhss.2019.103.0341

ISSN online: 2316-7750

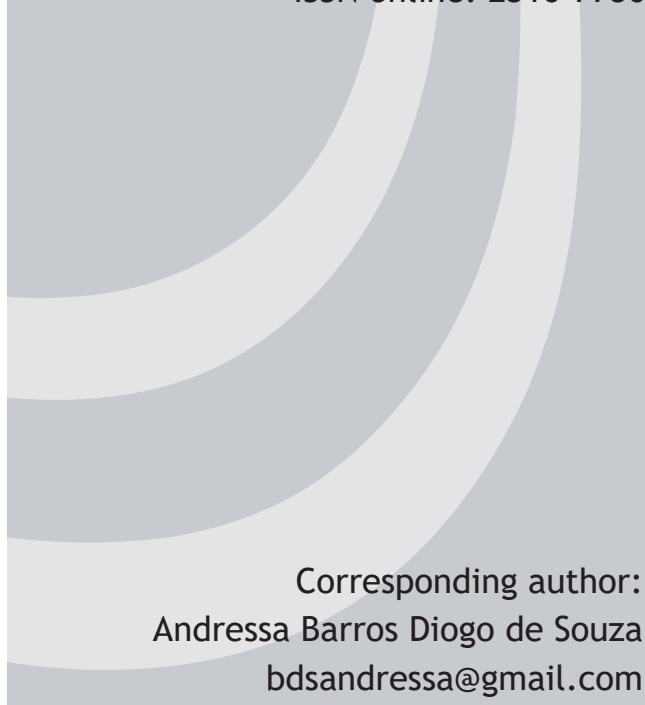




\section{Introduction}

Cancer is a set of more than 100 diseases, having disordered and rapid cell growth in common. This growth tends to be aggressive, determining the formation of malignant tumors, which can spread to other body regions ${ }^{1}$.

One of the cancer treatment alternatives is pharmacological therapy, with the use of antineoplastic drugs. Although treatment is effective in most of the cases, these medications can cause a variety of adverse reactions, generating patient discomfort ${ }^{2}$. The most commonly observed adverse reactions are nausea, vomiting and anorexia, with possible effect on the emotional state ${ }^{3}$.

In cancer patients emesis may come from several factors'. Regardless of the source of these adverse reactions, there is a considerable negative impact on the quality of life of the patients. Failure to use the correct antiemetic alters the nutritional status, eliminates the pleasure of drinking and eating and can increase the costs of treatment ${ }^{5,6}$. The NCCN protocol was chosen because, apart from the hospital not having an emesis prevention protocol, this was the most appropriate and flexible protocol against the standardization of hospital medications. One reason is that this protocol provides for the use of dexamethasone $20 \mathrm{mg}$ administered via IV/VO if the NK1 antagonist is not available and that's what happens in the unit of study. The present study was proposed due to the hypothesis generated in the sector, where prevention of acute emesis may not be performed adequately in patients who used injectable antineoplastic medications.

This study aimed to evaluate the compliance of the prescription of antiemetic drugs from pre-chemotherapy of patients in a public hospital of Rio de Janeiro, according to the 2017 protocol for the prevention of acute emesis of the NCCN.

\section{Methods}

A retrospective and cross-sectional study of the analysis of chemotherapy prescriptions, conducted from January to April 2017 in a public hospital in Rio de Janeiro. Based on the National Comprehensive Cancer Network (NCCN) (2017), the injectable medications standardized in the hospital were related to their respective emetogenic risk. For a regimen with more than one drug, the emetogenic risk was determined considering the most emetogenic drug of the prescription? ${ }^{7}$.

Pre-chemotherapy was evaluated to include all prescriptions of injectable antineoplastic medications during the evaluated period, except for pediatrics and for patients using methotrexate. Those exclusion criteria were adopted to avoid bias in the study as the protocols for this group are differentiated. During the study period there was no shortage of the antiemetic drug, thus not influencing prescriptions. To assess whether pre-chemotherapy was performed correctly, the following data were collected and stored in an Excel table: date of the prescription, medical records, gender, age, chemotherapy drugs used, dose of the chemotherapy drug, classification of the emetogenic risk, pre-chemotherapy antiemetics, dose, route of administration and frequency of administration.

After collection, the data were compared with the international protocol of prevention of acute emesis of the $\mathrm{NCCN}$ (2017) and it was assessed if pre-chemotherapy was being performed in accordance with this protocol. When pre-chemotherapy was performed accordingly, the word "Yes" was signaled and, when not, the word "No".

All non-compliant prescriptions were classified as follows: wrong medication (too much or too little); wrong dose; wrong frequency of administration and wrong administration route.

The prescription was classified as wrong drug when too much or too little of a drug was prescribed against the recommended in the protocol; wrong dose when the dose was below or above the recommended one; wrong frequency of administration when the frequency was below or above the recommended; and wrong route of administration when not in accordance with the recommended.

The project was approved by the UFF Research Ethics Committee Antônio Pedro University Hospital/Medical School of the Fluminense Federal University (HUFMUFF) (number 093369/2017; CAAE 73665017.8.0000.5243), on September 28 $8^{\text {th }}, 2017$.

\section{Results}

From January to April 2017 there were 1,072 prescriptions, of which 919 could be analyzed. Those not analyzed were with incomplete information such as dose, frequency, making impossible to include them in the study. Of those analyzed, $60.8 \%$ belonged to female individuals, with a mean age of 59 years old for both genders. With respect to the prescribed antineoplastics, $37.75 \%$ had low emetogenic risk, while $36.88 \%$ presented moderate risk (Table 1). Of the antiemetic drugs prescribed, 77\% (704) were the combination of ondansetron + dexamethasone. Of the 919 prescriptions, only $17 \%$ were in accordance with the NCCN protocol? ${ }^{7}$ Prescriptions containing medications with moderate and low emetogenic risk were the ones which most showed a nonconformity Relation with the protocol used: $37 \%$ and 35\%, respectively. (Table 1)

Table 1. Characteristics of the patients, emetogenic risk and compliance found in the prescriptions

\begin{tabular}{|c|c|c|c|c|c|}
\hline Prescriptions & $\mathrm{N}(\%)$ & & & & \\
\hline \multicolumn{6}{|l|}{ Gender } \\
\hline Male & \multicolumn{5}{|l|}{$360(39.8)$} \\
\hline Female & \multicolumn{5}{|l|}{$559(60.8)$} \\
\hline \multicolumn{6}{|l|}{ Age (years old) } \\
\hline Mean & \multicolumn{5}{|l|}{59.1} \\
\hline Median & \multicolumn{5}{|l|}{60} \\
\hline Maximum & \multicolumn{5}{|l|}{84} \\
\hline Minimum & \multicolumn{5}{|l|}{20} \\
\hline Standard deviation & \multicolumn{5}{|l|}{11.64} \\
\hline \multicolumn{6}{|l|}{ Emetogenic risk } \\
\hline High & \multicolumn{5}{|l|}{$130(14.1)$} \\
\hline Moderate & \multicolumn{5}{|l|}{$339(36.9)$} \\
\hline Low & \multicolumn{5}{|l|}{$347(37.8)$} \\
\hline Minimum & \multicolumn{5}{|l|}{ 103(11.1) } \\
\hline \multicolumn{6}{|c|}{$\begin{array}{l}\text { Compliance analysis of the pre- } \\
\text { chemotherapy prescriptions }\end{array}$} \\
\hline & & Minimum & Low & Moderate & High \\
\hline Compliant (\%) & & 6 & 2 & 1 & 8 \\
\hline Not compliant (\%) & & 5 & 35 & 37 & 6 \\
\hline
\end{tabular}

Source: Evaluation of the pre-chemotherapy antiemetic prescriptions in a hospital unit. 2018. By the author.

Among the nonconforming prescriptions, the most found nonconformity was wrong dose (42\%) (Table 2), and the most prevalent scenario was the prescription of dexamethasone above the recommended dose (63\%). This noncompliance was observed again in $26 \%$ of the prescriptions, associated with excess medication and with wrong route of administration in those that prescribed IV (intravenous) instead of $\mathrm{VO}$ (oral) ondansetron.

The prescription of a drug with the wrong dose was mainly associated to high and moderate emetogenic risks. The non-conformity most associated with minimal emetogenic risk was wrong medication, $100 \%$ due to the prescription of excess medication. This result is justified with the protocol used, because with minimal emetogenic risk medications no antiemetic therapy is necessary.

\section{Discussion}

In cancer patients, emesis may be related to the clinical profile of the neoplasm itself, with the toxicity of the treatment or with the factors of the patient4.

Women are at a higher risk than men; there is a low incidence in children less than six years old and in individuals over 50 years old; there is a lower incidence in alcoholics; anxiety raises the risk; improper control of emesis in previous chemotherapies raises the risk ${ }^{4}$. In patients with intestinal sub-occlusion or metastasis to the central nervous system and the liver, these symptoms occur more frequently ${ }^{4}$. If an adequate antiemetic prophylaxis is not performed, nausea and vomiting occur in up to $80 \%$ of the patients receiving chemotherapy. The use of antiemetics can lead to an improvement in the symptoms of nausea and vomiting triggered by the chemotherapy treatments in about $25 \%$ to $50 \%$ of the patients ${ }^{9}$. In the present study, the compiled results show that $83 \%$ of the Prescriptions did not comply with the 2017 NCCN Guideline. In a study conducted in the Albert Einstein Israeli Hospital, in which the ASCO Guideline ${ }^{10}$ was used, low compliance with the protocol used $(22 \%)^{11}$ was also found. 
Table 2. Classification of the nonconformities in the prescription.

\begin{tabular}{|c|c|c|c|c|}
\hline & $\mathbf{n}$ & $\%$ & Mean & $\begin{array}{l}\text { Standard } \\
\text { deviation }\end{array}$ \\
\hline Total of prescriptions & 919 & & & \\
\hline Total of nonconformities & 763 & 83.0 & 95.4 & 113.0 \\
\hline \multicolumn{5}{|l|}{ Types of nonconformities } \\
\hline Wrong dose & 317 & 34.5 & & \\
\hline $\begin{array}{l}\text { Wrong medication/Wrong } \\
\text { dose/Wrong route of } \\
\text { administration }\end{array}$ & 200 & 21.8 & & \\
\hline Wrong medication & 110 & 12.0 & & \\
\hline $\begin{array}{l}\text { Wrong medication/Wrong } \\
\text { route of administration }\end{array}$ & 95 & 10.3 & & \\
\hline $\begin{array}{l}\text { Wrong medication/Wrong } \\
\text { frequency of administration }\end{array}$ & 16 & 1.7 & & \\
\hline Wrong route of administration & 13 & 1.4 & & \\
\hline Wrong medication/Wrong dose & 8 & 0.9 & & \\
\hline $\begin{array}{l}\text { Wrong route of administration/ } \\
\text { Wrong frequency of } \\
\text { administration }\end{array}$ & 4 & 0.4 & & \\
\hline
\end{tabular}

Source: Evaluation of the pre-chemotherapy antiemetic prescriptions in a hospital unit. 2018. By the author.

In the global literature, the overall adherence rate of antiemetic prescriptions to the national or international antiemetic guidelines has varied from $20 \%$ to $61.9 \% 12-17$.

As demonstrated in a prospective observational study of patients who received high and moderate risk regimens, individuals who have in their prescription antiemetics which are consistent with the guidelines have less nausea and vomiting than those who are prescribed with regimens that are inconsistent with the guidelines ${ }^{18}$

Even though there is evidence to suggest that the administration of the antiemetic prophylaxis recommended by the guidelines correlates with an adequate control of nausea and vomiting, some studies also report that adherence to the antiemetic guidelines does not occur as it should ${ }^{19-22}$.

Most of the prescriptions (77\%) contained the combination of ondansetron + dexamethasone. When combined with ondansetron, dexamethasone acts as a Powerful antiemetic, with a response rate of $15 \%$ to $20 \%$ higher $^{23}$. That can justify the high prescription rate of this drug combination in this research. In one study it was shown that, in combination with ondansetron, dexamethasone obtained an acute emesis protection rate of $72 \%$ of the patients ${ }^{24}$.

Prescribing a drug at the wrong dose, which was the prescription error most commonly found (42\%) may not be effective for the prevention of emesis, apart from possibly being harmful to the patient. The administration of drugs by a not recommended route in this case may not cause many problems for the patient because the presentation of ondansetron IV is available in the market, but it should be thought that in some cases the oral medication is cheaper, less invasive and equally effective. This fact is also debatable, since the patient's condition is to be known and whether the patient is able to take the medication orally. Because there was no access to the medical record of the patient, the clinical condition becomes a bias.

What could also be observed in this study was that the prescription of antiemetics for moderate emetogenic risk was made according to the high emetogenic risk, with higher doses of dexamethasone and that, for moderate risk, only one prescription was made with the correct dose of dexamethasone.

Prescribing a wrong drug (too much or too little) may not prevent emesis and vomiting effectively, apart from $\}$ increasing the possibility of adverse reactions Although combined dexamethasone and ondansetron act as a powerful antiemetic, it does not require the prescription of this combination for all emetogenic risks.

It is estimated that $30 \%$ of the money invested in health could be saved without reducing the quality of care offered if there was adherence to the guidelines ${ }^{25}$.

A study conducted in 2013 by ASCO, another clinical oncology society, published a list of important practices in oncology, in which one of the points is the use of antiemetics indicated for high risk emetogenic chemotherapies in chemotherapies with low or moderate risk. This largely reflects this study, where the main reason for non-compliance is the dose and excess medication ${ }^{26}$.

\section{Conclusions}

From this study it can be concluded that most of the prescriptions analyzed did not comply with the pre-established protocol.

Failure to follow the protocol is of concern because it increases the likelihood of an adverse drug reaction occurring, prolongs hospitalization time, does not effectively prevents emesis thereby increasing patient weakness, increases the suffering of the person who is already suffering due to chemotherapy, and decreases quality of life, as well as wasted resources. In addition to reducing complications, an effective treatment can decrease the number of treatment dropouts.

This study has limitations because it was performed retrospectively, so we did not follow the patient to verify if, in the practice, this protocol would be effective for the patients of the unit, taking into account the particularities of the disease, age, and lifestyle. In addition, the study was conducted in a single unit and thus the results cannot be generalized, despite these results being similar to data found in the literature.

The hospital in the study setting has no emesis prevention protocol. Therefore, I suggest using the NCCN (2017) protocol, due to the importance of practicing the rational use of these medications and mainly of preventing nausea and vomiting in oncologic patients, giving them more comfort, and promoting patient safety and treatment effectiveness.

\section{Funding sources}

The authors declare that the research did not receive funding for its realization.

\section{Contributors}

$\mathrm{ABDS}$ and $\mathrm{BCC}$ conceived the project; $\mathrm{ABDS}$ collected the data; ABDS analyzed the data; $\mathrm{ABDS}$ interpreted the data; $\mathrm{ABDS}$ wrote the article; $\mathrm{ABDS}$ and $\mathrm{BCC}$ reviewed the article critically. $\mathrm{ABDS}$ and $\mathrm{BCC}$ approved the final version to be published. All the authors are responsible for all the aspects of the paper in ensuring accuracy and integrity of any part of the work.

\section{Conflicts of interests}

The authors declare no conflicts of interest.

\section{References}

1. Instituto Nacional Do Câncer (INCA). O que é câncer? Rio de Janeiro, 2016. Disponível em: <http://wwwl.inca.gov.br/conteudo_view.asp?id=322>. Access in December 12,2016.

2. BeckerJ,NardinJM.Utilização de antieméticos no tratamento antineoplásico. Rev Bras Farm Hosp Serv Saúde. 2011;2(3):18-22.

3. Kaley TJ, Deangelis LM. Therapy of che motherapy-induced peripheralneuropathy. Nova York, BrJ Haematol. 2009;145(1):3-14.

4. Francisco MFR. Abordagem não farmacológica no controle das náuseas evômitos induzidos pela quimioterapia. Lisboa, Onco News, 2008;2(6):12-16.

5. Aapro M. Optimising antiemetic therapy: what are the problems and how canthey be overcome? Genolier, Curr Med Res Opin. 2005; 21(6): 885-897.

6. Bloechl-Daum B, Deuson RR, Mavros P, et al. Delayed nausea and vomitingcontinue to reduce patients' quality of life after highly and moderatelyemetogenic chemotherapy despite antiemetic treatment. Vienna, J Clin Oncol. 2006; 24(27):4472-4478.

7. NCCN Clinical Practices Guidelines in Oncology. Antiemesis. Version 2.2017.Disponivel em:https://www.nccn.org/professionals/physician_gls/ PDF/antiemesis.pdf. Access in July 29, 2017.

8. Naeim A, Dy SM, Lorenz KA, et al. Evidence-based recommendations forcancer nausea and vomiting. Los Angeles, J Clin Oncol. 2008; 26(23):3903-3910. 
9. Sanger GJ, Andrews PL. Treatment of nausea and vomiting: gaps in ourknowledge. Londres, Auton Neurosci. 2006; 129(1-2):3-16.

10. Basch E, Prestrud AA, Hesketh PJ, et al. Antiemetics: American Society ofClinical Oncology clinical practice guideline update. Alexandria. J Clin Oncol.275 2011;29(31):4189-98. Review. Erratum in: J Clin Oncol. 2014;32(19):2117

11. França MS, Junior PLU, Antunes YP, et al. Assessment of adherence to theguidelines for the management of nausea and vomiting induced bychemotherapy. São Paulo. Einstein. 2015;13:221-225.

12. Aapro M, Molassiotis A, Dicato M, et al. The effect of guideline-consistent antiemetic therapy on chemotherapy-induced nausea and vomiting (CINV) the Pan European Emesis Registry (PEER). Ann Oncol 23: 1986-1992, 2012

13. Hesketh PJ, Bohlke K, Lyman GH, et al. Antiemetics: American Society of Clinical Oncology focused guideline update. J Clin Oncol. 2016; 34:381-386.

14. Ruhlmann CH, Christensen TB, Dohn LH, et al: Efficacy and safety of fosaprepitant for the prevention of nausea and emesis during 5 weeks of chemoradiotherapy for cervical cancer (the GAND-emesis study): a multinational, randomised, placebocontrolled, double-blind, phase 3 trial. Lancet Oncol. 2016; 17:509-518.

15. Navari RM, Qin R, Ruddy KJ, et al. Olanzapine for the prevention of chemotherapy-induced nausea and vomiting. N Engl J Med. 2016; 375:134142

16. Nakamura F, Higashi T: Pattern of prophylaxis administration for chemotherapyinduced nausea and vomiting: an analysis of city-based health insurance data. Int J Clin Oncol. 2013; 18:971-976.

17. Aseeri M, Mukhtar A, Al Khansa S, et al. A retrospective review of antiemetic use for chemotherapy-induced nausea and vomiting in pediatric oncology patients at a tertiary care center. J Oncol Pharm Pract. 2013; 19:138-144.

18. Gilmore JW, Peacock NW, Gu A, Szabo S, et al. Antiemetic guideline consistency and incidence of chemotherapy-induced nausea and vomiting in US community oncology practice: INSPIRE Study. J Oncol Pract. 2014; 10:68-74.

19. Aapro M, Molassiotis A, Dicato M et al. The effect of guideline-consistent antiemetic therapy on chemotherapy-induced nausea and vomiting (CINV) the Pan European Emesis Registry (PEER). Ann Oncol. 2012; 23(8):1986 1992.

20. Gilmore JW, Peacock NW, Gu A et al Antiemetic guideline consistency and incidence of chemotherapy-induced nausea and vomiting in US community oncology practice: INSPIRE study. J Oncol Pract. 2014; 10(1):68-74.

21. Affronti ML, Schneider SM, Schlundt S et al. Adherence to antiemetic guidelines in patients with malignant glioma: a quality improvement project to translate evidence into practice. Support Care Cancer. 2014; 22(7):18971905 .

22. Roeland E, Aapro MS, Schwartzberg LS. Advances in the Management of Chemotherapy-Induced Nausea and Vomiting: New Data From Recent and Ongoing Trials. Clin Adv Hematol Oncol. 2015; 13(10):1-14

23. Lohr L. Chemotherapy-induced nausea and vomiting. Minneapolis, Cancer J. 2008. 14(2): 85-93.

24. Abali H, Celik I. Tropisetron, ondansetron, and granisetron for control ofchemotherapy -induced emesis in Turkish cancer patients: a comparison ofefficacy, side-effect profile and cost. Mersin, Cancer Invest. 2007;25(3):135 272 .

25. Kenefick H, Lee J, Fleishman V. Barriers to guidelines adherence.
Improvingphysician adherence to clinical practice guidelines: barriers and strategies forchange. Cambridge, New England Healthcare Institute; 2008.

26. Schnipper LE, Lyman GH, Blayney DW, et al. American Society of ClinicalOncology 2013 top five list in oncology. Boston, J Clinl Oncol. 2013;31(34):4362-4370. 